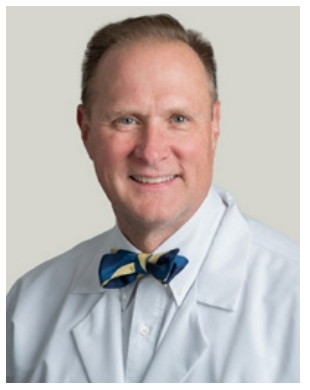

\title{
A Short Editorial Offering Congratulations to the Journal
}

\author{
Douglas R. Nordli, MD \\ Department of Pediatrics, University of Chicago, Chicago, IL, USA
}

Received: July 15, 2020

Accepted: July 17, 2020

Corresponding author:

Douglas R. Nordli, MD

Department of Pediatrics,

University of Chicago,

Maryland Avenue, Chicago,

IL 60637, USA

Tel: +1-773-702-6169

Fax: +1-773-702-4786

E-mail:dnordli@peds.bsd.

uchicago.edu
Dear Member of the Editorial Board,

Thank you for allowing me to take this opportunity to congratulate you all on the decision of the Content Selection and Advisory Board of SCOPUS to include Annals of Child Neurology into SCOPUS. This is a wonderful achievement and it reflects positively on the hard work and daring initiative of the board. This success was also achieved in a remarkably short period of time. In many ways, it parallels the larger extraordinary academic achievements of child neurology in South Korea. In my opinion, based on years of association with many Korean child neurologists and first hand experience gleaned by attending your professional meetings, this decision underscores the fact that child neurology in South Korea is second to none. Even though child neurology is a relatively new specialty within South Korea the world has already benefited from the many professional contributions that have been accepted into the most prestigious academic neurological journals. Now, Annals of Child Neurology has passed another milestone of international professional recognition which will allow even more contributions to be shared with the greater child neurology community. The pace of progress is very impressive. Godspeed.

Sincerely,

Douglas R. Nordli Jr, MD

\section{Conflicts of interest}

No potential conflict of interest relevant to this article was reported.

\section{ORCID}

Douglas R. Nordli, https://orcid.org/0000-0002-1617-0667 